\title{
Is the Impact of a Support System on Job Satisfaction Different between Employees in Taiwan and Mainland China?
}

\author{
Chun-Yi Lu (1) \\ College of Education, National Taiwan Normal University, Taiwan \\ Email: education8300@gmail.com
}

How to cite this paper: Lu, C.-Y. (2019). Is the Impact of a Support System on Job Satisfaction Different between Employees in Taiwan and Mainland China? Chinese Studies, 8, 49-66.

https://doi.org/10.4236/chnstd.2019.83005

Received: April 2, 2019

Accepted: August 9, 2019

Published: August 12, 2019

Copyright $\odot 2019$ by author(s) and Scientific Research Publishing Inc. This work is licensed under the Creative Commons Attribution International License (CC BY 4.0).

http://creativecommons.org/licenses/by/4.0/

Open Access

\begin{abstract}
From the perspective of social exchange theory (SET), the study examines a mediated model linking perceived human resource management (HRM) practices and perceived supervisor support (PSS) with work engagement and job satisfaction. This study also empirically investigates the invariance of sub-groups among 1362 full-time employees recruited from Taiwan and Mainland China. The results show that work engagement strongly was linked to job satisfaction and mediated the relationship between perceived HRM practices and PSS. In addition, no significant of different groups is evident in the structural relations among the employees in Taiwan and Mainland China. The findings suggest that the enactment of positive behavioral outcomes because of engagement and job satisfaction largely depends on organizational support, including HRM practices and supervisor encouragement.
\end{abstract}

\section{Keywords}

Perceived Human Resource Management Practice, Perceived Supervisor Support, Work Engagement, Job Satisfaction, Invariance Measurement

\section{Introduction}

Human resource management (HRM) practices are crucial for assisting new employees in assimilating into the workplace, thus optimizing their work efficiency and career development. In recent years, given that businesses have paid increasing attention to ensure a healthy work environment and atmosphere, several studies have examined the effects of perceived HRM practices on work engagement (Alfes, Shantz, Truss, \& Soane, 2013a; Bal, Kooij, \& De Jong, 2013). Organizational support and a congenial work atmosphere can encourage em- 
ployees to hold positive perceptions toward their jobs, for which supervisor support and encouragement play a critical role (Karatepe, 2014). Given that supervisors are organizational agents for employees (Eisenberger, Stinglhamber, Vandenberghe, Sucharski, \& Rhoades, 2002), care and encouragement expressed officially or unofficially by supervisors are conducive to developing a happy and focused work attitude among employees (Durham, Knight, \& Locke, 1997). Although HRM practices and supervisor support contribute to employee work engagement, few previous studies have discussed or verified their association with job satisfaction. From the perspective of social exchange theory (SET), effective HRM practices can be utilized to create a sense of employee achievement and satisfaction by improving their confidence and morale, increasing their energy and passion, and developing a sense of devotion toward the organization and their peers (Alfes, Truss, Soane, Rees, \& Gatenby, 2013b; Giallonardo, Wang, \& Iwasie, 2010), similarly, expressing consistent support and care to employees' concerns while offering timely assistance and encouragement enhances work engagement and job satisfaction (Karatepe, 2014; Swanberg, Mckechnie, Ojha, \& James, 2011). However, whether work engagement plays a mediating role in this relationship requires further investigation.

The influence of a Confucian heritage culture means that people in Chinese Mainland and Taiwan share identical cultural aspects and characteristics. Employees in these different regions, however, have different perceptions of and responses to job satisfaction (Lu, 2009; Lu, Cooper, Kao, \& Zhou, 2003). Differences in the economic development and political systems between the two regions have led to the development of different HRM practices and work values between people in Chinese Mainland and Taiwan. However, employees in Chinese Mainland and Taiwan have become increasingly appreciative of the value of a positive work atmosphere and quality of life in recent years. Thus, when organizations fail to meet their employees' expectations or when employees perceive that they are not receiving support or encouragement from their supervisors, employee retention decreases and turnover rates increase. Organizations and supervisors should therefore examine their employees' work engagement and job satisfaction (Alarcon \& Lyons, 2011; Alfes et al., 2013b). Few existing studies have investigated whether the perceptions of employees in Chinese Mainland and Taiwan differ with regard to work engagement and job satisfaction and whether cultural differences contribute to differences in how they perceive HRM practices and supervisor support. Previous studies have found that employees' life and work affected by sub-cultural influences formed by the societal, political, and economic developments in each region, thus highlighting that the equivalence of measurements is the primary problem in data analysis (Chen \& $\mathrm{Lu}$, 2013). Singh (1995) suggested that when performing cross-cultural analyses, model equivalence tests should be conducted to demonstrate that the models established by researchers are consistent across cultural groups. The present study therefore examines the impact of two different groups in this context.

The aims of this study are to a) discuss the relationship among perceived 
HRM practices, perceived supervisor support (PSS), work engagement, and job satisfaction; b) examine the mediating effect of work engagement on the relationships of perceived HRM practices and job satisfaction, moreover, work engagement mediates the relationship of PSS and job satisfaction; and c) observe whether these relationships vary between employees in Chinese Mainland and Taiwan because of different region and culture. The contributions of this study are as follows. From the perspective of positive psychology, work engagement and job satisfaction are critical factors that determine whether employees work healthily or live happily (Alarcon \& Lyons, 2011). The present study proposes a comprehensive theoretical framework for work engagement based on the concepts of positive work environments and work attitude. Second, as previous studies have mostly considered work engagement as a component of job satisfaction and have seldom focused on the differences between work engagement and job satisfaction, this study adopts a cross-national perspective (Singh, 1995) to compare groups of employees in Chinese Mainland and Taiwan. Third, we adopt measurement invariance to examine the proposed models through cross validation to further elucidate the differences between the perceptions of employees in Taiwan and Chinese Mainland toward the workplace.

\section{Theoretical Background and Hypotheses}

\subsection{HRM Practices, Supervisor Support, Work Engagement and Job Satisfaction}

Economic development, intergenerational differences, and improvements in the quality of labor have led to increasingly diverse perceptions, needs, and values in the workplace. While commitment and effort in the workplace were essential forms of work compensation, employees' work engagement and job satisfaction have become increasingly valued in attracting and retaining talents and enabling them to work happily (Eisenberger et al., 2002). According to Blau (1964), trust relationships in organizations can be divided into organization-member exchanges (OMXs) and leader-member exchanges (LMXs), and support systems are crucial for employee retention and happiness. Support systems are categorized as organizational and supervisor support systems (Eisenberger et al., 2002). HRM practices are a typical example of organizational support. For organizations, positive HRM practices (e.g. attendance, salary management, and job instruction) not only increase work involvement and sensitivity among employees, as indicated by the principles of reciprocity and mutual benefit (Benn, Teo, \& Martin, 2015), but they also affect employees' job satisfaction and willingness to work (Alfes et al., 2013a). Supervisor support also plays a critical role in an organization's support system because the LMX relationship affects the OMX relationship, which can be attributed to supervisors (as organizational agents) offering timely information or feedback influencing the work attitude, behavior, and performance of employees and their perceptions toward the organization for which they work (Karatepe, 2014; Paillé, Grima, \& Bernardeau, 2013). Supervisors therefore represent or act as spokespersons for their organizations. When 
perceiving supervisor support, employees will typically believe that supervisors appreciate their contributions and care about their welfare, thus compensating the supervisors or organizations with extra-role performance behaviors (Cole, Bruch, \& Vogel, 2006).

Psychological willingness to engage in work represents a positive work-related state of mind, defined as vigor, dedication, and absorption at work, which enables employees to gain mental resilience and persistence when faced with challenges (Schaufeli, Bakker, \& Salanova, 2006). These factors lead to positive reactions and attitudes toward work. Whereas previous studies have focused mostly on work performance, recent research has shown a connection between work engagement and job satisfaction. This shift in focus arises due to the growing importance of positive psychology in work environments, which has drawn attention to employee job satisfaction (Alarcon \& Lyons, 2011; Benn et al., 2015; Giallonardo et al., 2010). SET suggests that when employees perceive adequate HRM practices and supervisor support, they are inclined to increase their work involvement as a form of compensation, which leads to a sense of increased enjoyment and satisfaction. In other words, when perceiving a positive influence of HRM practices and supervisor support, employees tend to attain job satisfaction through work engagement (Alfes et al., 2013a, 2013b; Christian, Garza, \& Slaughter, 2011; Saks, 2006). We thus propose the following hypotheses:

Hypothesis 1: Perceived HRM practices are positively related to work engagement.

Hypothesis 2: PSS is positively related to work engagement.

Hypothesis 3: Work engagement is positively related to job satisfaction.

\subsection{The Mediating Effect of Work Engagement}

The term work engagement carries a connotation of dedication and devotion and represents a positive attitude or mindset toward work that can be reflected by employees' internal motivation and values. When employees have access to use HRM practices, they are likely to reciprocate, not only through higher engagement, but also by contributing to a higher degree of job and satisfy with their job (Bal \& De Lange, 2015). Meanwhile, supervisors are the main entity realizing employees' work, and holding the authority to evaluate employee performance, supervisors' supports are often the other main reason why employees are engaging in work (Eisenberger et al., 2002). Work engagement is affected by numerous factors such as intergenerational differences, increased awareness of gender equality, and advancements in information technology (Bal et al., 2013; Bal \& De Lange, 2015).

Kahn (1990) defined work engagement as roles that people perform to express themselves physically, cognitively, and emotionally at work, showing that work engagement is determined by differences in personal behaviors or attitudes toward work, can exist in various forms, and be influenced by numerous factors 
(Rich, LePine, \& Crawford, 2010). Job satisfaction, organizational commitment, and organizational citizenship behavior have typically been defined as the outcome variables in research on employee work behavior (Alfes et al., 2013b). However, few empirical studies have discussed the mediating effects of external or organizational factors on the relationship between employee behavior and these outcome variables. Thus, the present study employed work engagement as a mediating variable to examine its influence on the perceived HRM practices-job satisfaction and PSS-job satisfaction relationships. We therefore posit the following hypotheses:

Hypothesis 4: Work engagement mediates the relation between perceived HRM practices and job satisfaction.

Hypothesis 5: Work engagement mediates the relation between PSS and job satisfaction.

\subsection{Invariance Measurement}

Although Chinese Mainland and Taiwan both affected by Confucian culture, their different political, economic, and social development has led to the formation of unique subcultures, which influence their work and lifestyles (Chen \& Lu, 2013). Previously, entrepreneurs in Taiwan employed various management models or strategies when opening factories in Chinese Mainland. However, after years of cross-strait exchange, cooperation, and learning in addition to rapid economic development and increased internet access in Chinese Mainland have led to change in work values among employees in both Chinese Mainland and Taiwan. Although Chinese organizations typically emphasize the importance of employee loyalty and engagement (Hofstede \& McCrae, 2004), employee rights and quality of working life have received greater attention from many studies recently because employees consider their rights at work to be critical factors in deciding whether they stay at their current organization. Organizations must therefore respond to this trend in Chinese Mainland. In addition, manufacturing entrepreneurs in Taiwan should adjust the management models they apply in factories established in Chinese Mainland and Taiwan.

Because employees in these two regions are characterized by different work values, attitudes toward life, leadership styles, and personal development, many of which are attributable to lifestyle differences and from living for many years under distinct political and educational systems (Shi, 2001). Several empirical studies have confirmed the differences in job satisfaction and leadership styles between employees in Chinese Mainland and Taiwan (Hsu \& Chen, 2011). In addition, the localization of HRM practices in subsidiaries in Chinese Mainland is influenced by cultural differences. To compare respondents in Chinese Mainland and Taiwan in groups to identify cross-cultural factors (Byrne, 2004; Cheung \& Rensvold, 2002; Little, 1997), the present study used measurement invariance to observe cross-strait differences through the measurement and structural models of the proposed research framework. We therefore propose the following hypothesis: 
Hypothesis 6: The research model of measurement equivalence is different between employees in Taiwan and Mainland China.

\subsection{Research Model}

Figure 1 shows our research model, which tests the relationship among perceived HRM practices, PSS, work engagement (WE), and job satisfaction (JS). As this study also examines measurement equivalence, the focus of the model is shifted to demonstrate whether two single-sample groups have different responses to this model.

\section{Methods}

\subsection{Samples}

We drew our sample from four large Taiwan industrial companies which set up factories both in Taiwan and Mainland China. The study adopted a prospective design with data being collected in two waves. In the first wave, employees in Chinese Mainland and Taiwan of grass-roots completed standard measures of the components of perceived human resource management practice, perceived supervisor support, work engagement. Two months later, employees' self-reported job satisfaction was measured in the second wave of data collection. A total of 1729 survey forms were circulated. The final respondents of 1362 consisted of two subgroups including 543 employees in Taiwan and 819 employees in Chinese Mainland were valid for analysis (valid return rate is $78.8 \%$ ). The sample characteristics were illustrated as follows: $66.7 \%$ were male employees; $33.1 \%$ were from 30 to 39 years old; and $65 \%$ of respondents had less than 5 years of tenure. Table 1 provides a summary of the respondents' demographics.

\subsection{Measures}

All the participants responded to a structural questionnaire containing questions on demographic variables, perceived HRM practices, perceived supervisor support, work engagement and job satisfaction. Standardized back-translation techniques were used in the development of Chinese versions of the questionnaire (Brislin, 1986).

A 9-item scale developed by Gould-Williams \& Davies (2005) was to measure perceived HRM practices. A sample item was, "I am provided with sufficient opportunities for training and development of from my company". The response scale ranged from 1 (strongly disagree) to 6 (strongly agree) with a reliability coefficient of 0.91. Perceived supervisor support was measured using a short four-item scale (Paillé et al., 2013). A sample item was, "My supervisor is concerned about my welfare at work" rated on a six-point scale ranging from 1 (strongly disagree) to 6 (strongly agree) with a reliability coefficient of 0.89 . The nine-item Utrecht Work Engagement Scale (UWES) was used to measure work engagement (Schaufeli et al., 2006). The UWES consists of three sub scales for vigor, dedication, and absorption. Three items were measured each dimension of 


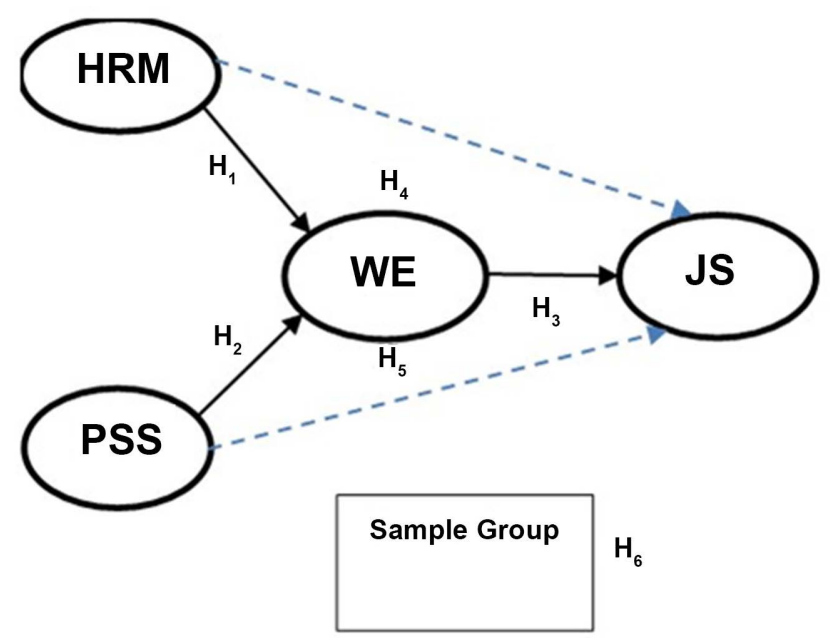

Figure 1. Research model.

Table 1. Respondent demographics.

\begin{tabular}{|c|c|c|c|}
\hline Measures & Items & Count & Percent (\%) \\
\hline \multirow{2}{*}{ Gender } & Male & 908 & 66.7 \\
\hline & Female & 454 & 33.3 \\
\hline \multirow{5}{*}{ Age } & $20-29$ & 366 & 26.9 \\
\hline & $30-39$ & 451 & 33.1 \\
\hline & $40-49$ & 293 & 21.5 \\
\hline & $50-59$ & 198 & 14.5 \\
\hline & $>59$ & 54 & 4.0 \\
\hline \multirow{6}{*}{ Tenure } & $<5$ & 886 & 65.1 \\
\hline & $5-10$ & 232 & 17.0 \\
\hline & $10-14$ & 146 & 10.7 \\
\hline & $15-19$ & 50 & 3.7 \\
\hline & $20-24$ & 38 & 2.8 \\
\hline & $>24$ & 10 & 0.7 \\
\hline \multirow{4}{*}{ Education } & High school & 648 & 47.6 \\
\hline & Bachelor's degree & 506 & 37.2 \\
\hline & Master's degree & 205 & 15.1 \\
\hline & Doctorate & 3 & 0.2 \\
\hline
\end{tabular}

work engagement. Each item was rated on a six-point scale ranging from 1 (never) to 6 (always). A sample item for vigor was, "At my work, I feel bursting with energy" with a reliability coefficient of 0.74 . Another sample item for dedication was, "I am enthusiastic about my job" with a reliability coefficient of 0.88 . The other sample item for absorption was, "I am immersed in my work" with a reliability coefficient of 0.73 . Job satisfaction was measured using the three-item MOAQ-JSS scale from Cammann, Fichman, Jenkins and Klesh (1983) with a re- 
liability coefficient of 0.78 . A sample item was, "In general, I like working here" rated on a six-point scale ranging from 1 (strongly disagree) to 6 (strongly agree). The research scales with the items were provided in the Appendix. Table 2 presents means and standard deviations for each scale, and inter-scale correlations for all study variables. The inter-scale correlations show the expected direction of association and, with one exception, are all significant at the $p<0.01$ level.

\section{Results}

\subsection{Measurement Model Analysis}

A confirmatory factory analysis (CFA) using AMOS19.0 was conducted to test measurement model and structural model. The $\chi^{2} /$ degree of freedom, comparative fit index (CFI), the non-normed fit index (NNFI), goodness of fit index (GFI), adjusted goodness of fit index (AGFI) and the root mean square error of approximation (RMSEA) were utilized as means for evaluating goodness-of-fit indices. Goodness-of-fit statistics for CFA are given in Table 3. Although $\chi^{2} /$ degree of freedom failed to meet the recommended maximum values. But the value meeting the criteria lower than 0.5 which Schumacker \& Lomax (2010) suggested led us to believe that the model fit was reasonably adequate to assess the result for the measurement and structural model.

The values of the average variance extracted (AVE) were compared with the squared correlations for all pairs of constructs (Fornell \& Larcker, 1981). The results showed that the AVE exceeded the squared correlation, indicating discriminant validity. Therefore, the measures adopted in our study were valid and internally consistent. Common method variance (CMV) may affect the results because the study data were collected through self-report questionnaires (Podsakfoff, MacKenzie, Lee, \& Podsakoff, 2003). The possibility of common method bias was tested using Harman's one factor test. A principal component factor analysis with varimax rotation was used on the items of perceived HRM practices, perceived supervisor support, work engagement, and job satisfaction. This

Table 2. Descriptive statistics and correlations for scale variables.

\begin{tabular}{|c|c|c|c|c|c|c|c|c|c|c|}
\hline & Mean & SD & 1 & 2 & 3 & 4 & 5 & 6 & 7 & 8 \\
\hline 1) Vigor & 5.05 & 1.26 & 1 & & & & & & & \\
\hline 2) Dedication & 4.29 & 1.06 & $0.558^{\star *}$ & 1 & & & & & & \\
\hline 3) Absorption & 4.83 & 0.97 & $0.474^{* *}$ & $0.575^{\star *}$ & 1 & & & & & \\
\hline 4) Job satisfaction & 4.98 & 1.31 & $00.953^{* *}$ & $00.546^{\star *}$ & $0.462^{\star *}$ & 1 & & & & \\
\hline 5) HRM practices & 4.29 & 1.02 & $00.483^{* *}$ & $0.745^{\star *}$ & $0.654^{* *}$ & $0.470^{* *}$ & 1 & & & \\
\hline 6) Superviosr support & 4.76 & 0.96 & $00.489^{* *}$ & $0.600^{\star *}$ & $0.900^{* *}$ & $0.471^{\star *}$ & $0.683^{* *}$ & 1 & & \\
\hline 7) Gender & 1.33 & 0.47 & 00.086 & -0.044 & 0.036 & 0.068 & -0.01 & -0.013 & 1 & \\
\hline 8) Tenure & 2.85 & 1.7 & -0.026 & -0.152 & -0.15 & -0.002 & -0.129 & -0.159 & -0.035 & 1 \\
\hline
\end{tabular}

${ }^{* *} p<0.01 ;{ }^{*} p<0.05$. 
Table 3. Fit indices for measurement and structural model.

\begin{tabular}{cccc}
\hline Fit indices & Recommended value & Measurement model & Structural model \\
\hline$\chi^{2} / \mathrm{df}$ & $\leq 3.00$ or $\leq 5.00$ & 3.42 & 3.34 \\
$\mathrm{NNFI}$ & $\geq 0.9$ & 0.97 & 0.971 \\
$\mathrm{CFI}$ & $\geq 0.9$ & 0.976 & 0.976 \\
$\mathrm{GFI}$ & $\geq 0.9$ & 0.953 & 0.953 \\
AGFI & $\geq 0.9$ & 0.935 & 0.935 \\
RMSEA & $\geq 0.08$ & 0.056 & 0.032 \\
\hline
\end{tabular}

result revealed multiple factors with eigenvalues greater than 1 . The first factor accounted for $30.1 \%$, lower than the cutoff suggested by Podsakoff \& Organ (1986). The results suggest that CMV was not a major problem for the data.

\subsection{Hypothesis Test}

The standardized path estimates from the first model indicate that the paths from perceived HRM practices to work engagement, PSS to work engagement, and work engagement to job satisfaction were positive and statistically significant, thus supporting $\mathrm{H}_{1}, \mathrm{H}_{2}$, and $\mathrm{H}_{3}$ (see Table 4).

The next two hypothesized models $\left(\mathrm{H}_{4}\right.$ and $\left.\mathrm{H}_{5}\right)$ are mediated, suggesting that work engagement mediates the relationships between perceived HRM practices and job satisfaction, and between PSS and job satisfaction. Based on the suggestions of Mackinnon (2008), we used 5,000 bootstrap samples to conduct mediation effect analysis (PROCESS Model 4; Hays, 2013) to test $\mathrm{H}_{4}$ and $\mathrm{H}_{5}$. The results showed that the indirect effect of work engagement on perceived HRM practices through job satisfaction (PSS as a control variable) was significant ( $\beta=$ $0.19,95 \% \mathrm{CI}=[0.135,0.268]$, zero not included). Further, the indirect effect of work engagement on PSS through job satisfaction (perceived HRM practices as a control variable) was significant $(\beta=0.35,95 \% \mathrm{CI}=[0.197,0.344]$, zero not included), thus supporting $\mathrm{H}_{4}$ and $\mathrm{H}_{5}$ (see Table 5).

\subsection{Invariance Analysis}

The objective of CFA was to check whether our measurement model had achieved measurement equivalence between Taiwan and Mainland China employees. Goodness-of-fit statistics for each single-sample group SEM models are given in Table 6. In each case, the model approached for a well-fitting model (Hu \& Bentler, 1999), that this model adequately accounted for the covariance matrices of the data from the two samples. The results of configural invariance analysis suggest that $\chi^{2}$ and fit indices for each employee group are good enough, providing evidence of the configural invariance of the construct (Cheung \& Rensvold, 2002; Kline, 2011).

Given that the SEMs were replicable in each single-sample, we conducted a series of multi-sample SEMs to identify variations in the measurement parameters 
Table 4. Path coefficient test.

\begin{tabular}{cccccc}
\hline Hypotheses & $\begin{array}{c}\text { Standardized } \\
\text { path coefficient }\end{array}$ & $\begin{array}{c}\text { Unstandardized } \\
\text { path coefficient }\end{array}$ & Standardized error & C.R. & $p$ \\
\hline HRM $\rightarrow$ WE & 0.234 & 0.214 & 0.046 & 5.133 & $* * *$ \\
PSS $\rightarrow$ WE & 0.433 & 0.321 & 0.056 & 7.685 & $* * *$ \\
WE $\rightarrow$ JS & 0.815 & 0.757 & 0.030 & 27.314 & $* * *$ \\
\hline
\end{tabular}

${ }^{* * *} p<0.0010$.

Table 5. Two mediated models test.

\begin{tabular}{ccccccc}
\hline \multirow{2}{*}{ WE as a mediator } & Estimates & SE & $\mathrm{Z}$ & \multicolumn{2}{c}{ Bootstrapping Percentile 95\% CI } \\
\cline { 6 - 7 } & & & & Lower & Upper \\
\hline $\begin{array}{c}\text { HRM } \\
\downarrow\end{array}$ & Total effects & 0.356 & 0.041 & 8.70 & 0.276 & 0.436 \\
JS & Indirect effects & 0.202 & 0.034 & 6.95 & 0.135 & 0.268 \\
& Direct effects & 0.154 & 0.030 & 5.15 & 0.095 & 2.213 \\
PSS & Total effects & 0.386 & 0.043 & 8.85 & 0.301 & 0.473 \\
$\downarrow$ & Indirect effects & 0.271 & 0.037 & 8.63 & 0.197 & 0.344 \\
JS & Direct effects & 0.116 & 0.032 & 3.59 & 0.053 & 0.179 \\
\hline
\end{tabular}

Table 6. Results of configural invariance analysis for sample group.

\begin{tabular}{cccccc}
\hline \multirow{2}{*}{ Sample group } & \multicolumn{5}{c}{ Goodness-of-fit statistics } \\
\cline { 2 - 6 } & $\chi^{2} / \mathrm{df}$ & CFI & GFI & AGFI & RMSEA \\
\hline Taiwan & 3.33 & 0.967 & 0.929 & 0.901 & 0.046 \\
Mainland China & 3.38 & 0.972 & 0.930 & 0.920 & 0.043 \\
\hline
\end{tabular}

and patterns of structural relationships among the constructs in the proposed model for Taiwan and Mainland China employees. Based on the invariance routine suggested by Byrne (2010), Cheung and Rensvold (2002), and Kline (2011), in which measurement parameters are initially constrained to be equivalent across two samples, such as factor loadings, measurement errors, latent factor variability, latent factor mean, or path coefficients, we used the hypothesized relationships among the model constructs to represent the structural parameters. Table 7 provides the goodness-of-fit indices for each model in the invariance routine and shows comparisons among these models are given in Table 7.

An initial baseline model was estimated to test whether the pattern of items and factors was feasible across the samples. This model demonstrated good fit with the data according to the multiple criteria adopted (Table 7, Model 1). Then we estimated a nested model that constrained the factor loadings to be invariant between two samples. Invariance of the factor loadings is considered the minimum acceptable criterion for measurement invariance (Byrne et al., 1989). The analysis resulted in a model that exhibited good fit with the data (Table 7 , Model 2). While the chi-square difference between Model 1 and Model 2 was 
Table 7. Goodness-of-fit statistics and model comparisons for two single-sample groups structural equation models.

\begin{tabular}{ccccccc}
\hline Model & Invariance test model & $\chi^{2}$ & $\mathrm{df}$ & CFI & NNFI & RMSEA \\
\hline 1 & configural invariance & 690.152 & 208 & 0.972 & 0.967 & 0.041 \\
2 & metric invariance & 711.596 & 213 & 0.971 & 0.967 & 0.041 \\
3 & intercept invariance & 734.577 & 216 & 0.969 & 0.966 & 0.042 \\
4 & factor variance & 744.397 & 218 & 0.969 & 0.966 & 0.042 \\
5 & error variance & 800.667 & 234 & 0.967 & 0.966 & 0.042 \\
\hline & Comparison & $\Delta \chi^{2}$ & $\Delta$ df & \multicolumn{1}{c}{$\Delta$ CFI } & \multicolumn{1}{c}{ N NNFI } \\
\hline & Model 1 vs. Model 2 & 21.444 & 5 & -0.001 & 0 \\
& Model 1 vs. Model 3 & 44.405 & 8 & -0.003 & -0.001 \\
& Model 1 vs. Model 4 & 54.245 & 10 & -0.003 & -0.001 \\
Model 1 vs. Model 5 & 110.515 & 26 & -0.005 & -0.001 \\
Model 2 vs. Model 3 & 22.981 & 3 & -0.002 & -0.001 \\
Model 2 vs. Model 4 & 32.801 & 5 & -0.002 & -0.001 \\
Model 2 vs. Model 5 & 89.071 & 21 & -0.004 & -0.001 \\
Model 3 vs. Model 4 & 9.82 & 2 & 0 & 0 \\
Model 3 vs. Model 4 & 66.09 & 18 & -0.002 & 0 \\
Model 4 vs. Model 5 & 56.27 & 16 & -0.002 & 0 \\
\hline
\end{tabular}

significant (Table 7), the incremental fit indices indicated that such a change reflected differences that were largely unsubstantial, as indicated by a change of .01 or less in the fit indexes (Cheung \& Rensvold, 2002).

Subsequent nested models in which the factor variances (variances of exogenous factors) and disturbances (variances of endogenous factors) (Table 7 , Model 3) and factor correlations between the exogenous predictors of HRM, PSS, WE, and JS factors (Table 7, Model 4), revealed substantial decrements in the fit indexes relative to the baseline model (Table 7). Modification indexes were used to identify parameters responsible for model misspecification. The indexes revealed that the factor variances and disturbances were mainly responsible for decrements in model fit and there was no significantly different between two samples. Finally, a model in which the structural paths were set to be equivalent across samples was estimated and revealed a decrement in goodness-of-fit indexes from baseline (Table 7, Model 5), but little change relative to the previous two models in the routine (Table 7) and there were few structural parameters that varied significantly across the samples. Modification indexes revealed that only two structural parameters were responsible for the misspecification: $\mathrm{HRM} \rightarrow$ JS and PSS $\rightarrow$ JS paths.

Given the high incidence of violating measurement invariance in different sample studies, these findings cast serious doubt on the conclusions drawn by previous studies. Thus, the impact of sample group factor is not significant for 
employees in Taiwan and Mainland China, and $\mathrm{H}_{6}$ was not supported.

Nevertheless, no significant difference was found for each model between the two samples. Table 8 shows the estimated standardized parameters for the structural relations among the latent constructs in the model of each sample. The results show that supervisor support was the sole predictor of job satisfaction with no significant direct effects of the Mainland China sample $(\beta=0.045$; $p>0.1$ ). Additionally, the impact of HRM practices on job satisfaction differs between employees in Taiwan and Mainland China $(z=-2.218 ; p<0.05)$.

\section{Conclusion}

SEM was employed to generate validated conclusions. First, when employees perceive their organization's HRM practices as important and meaningful, their work engagement and job satisfaction increase (Bal et al., 2013; Bal \& De Lange, 2015; Wright \& Boswell, 2002). Second, PSS is positively related to work engagement but exerts a relatively weak influence on job satisfaction. This finding can be attributed to supervisors' expectations of employees to demonstrate excellence at work; they thus focus more on their employees' work contributions than on their level of job satisfaction (Karatepe, 2014). The results of the present study showed that work engagement significantly mediates the perceived HRM practices-job satisfaction and PSS-job satisfaction relationships. In other words, perceived HRM practices can affect job satisfaction by influencing work engagement (Alfes et al., 2013a; Saks, 2006).

However, the coefficient for supervisor support on job satisfaction was weak, which can be attributed to PSS having the greatest effect on job satisfaction through its influence on work engagement (Christian et al., 2011; Karatepe, 2014; Paillé et al., 2013; Swanberg et al., 2011). A group analysis of respondents in Chinese Mainland and Taiwan suggested that the individual models for respondents in Chinese Mainland and Taiwan achieved an adequate fit, with no significant differences in any of the free parameters and coefficients. This finding suggests that no significant differences were detected regardless of the clustering model employed (Hsu \& Chen, 2011; Shi, 2001). However, there was a variation that was in keeping with this prediction for the influence of HRM practices on job satisfaction for the Taiwanese sample is more than Chinese Mainland sample. The reason may be influenced by analytical methods, theoretical

Table 8. Standardized parameter estimates for the structural equation model of each sample.

\begin{tabular}{cccc}
\hline Parameter & Taiwanese employees & Mainland China employees & z-score \\
\hline PSS $\rightarrow \mathrm{WE}$ & $0.437^{* * *}$ & $0.311^{* * *}$ & -1.090 \\
$\mathrm{HRM} \rightarrow \mathrm{WE}$ & $0.321^{* * *}$ & $0.221^{\star * *}$ & -1.035 \\
$\mathrm{WE} \rightarrow \mathrm{JS}$ & $0.733^{* * *}$ & $0.764^{* * *}$ & 0.521 \\
$\mathrm{HRM} \rightarrow \mathrm{JS}$ & $0.287^{* * *}$ & $0.118^{* * *}$ & $-2.218^{* *}$ \\
$\mathrm{PSS} \rightarrow \mathrm{JS}$ & $0.123^{*}$ & 0.045 & -0.857 \\
\hline
\end{tabular}

${ }^{* * *} p<0.01 ;{ }^{* *} p<0.05 ;{ }^{*} p<0.1$. 
development, characteristics of samples, or culture differences. Finally, no differences were observed between the respondents' perceptions in Chinese Mainland and Taiwan toward work-related mindsets, behaviors, and attitudes in the presence of cross-cultural differences.

\section{Theoretical Contributions}

Using SET a basis for discussing relationships of trust, reciprocity, and sharing within organizations and among employees, Blau (1964) proposed the concepts of HRM practices and supervisor support (Alfes et al., 2013b). The analysis in this study revealed that supervisor support and HRM practices both influence work performance and found that work engagement plays a critical role in the work environment because it is a self-induced behavior. In other words, when people are employed by an enterprise or organization, they receive organizational resources to perform their work duties and spontaneously engage in work (Bakker \& Demerouti, 2007). This finding is consistent with past research.

The present study distinguished work engagement from job satisfaction, including predisposing factors for work engagement (e.g., HRM practices and supervisor support), and employed job satisfaction as the outcome variable (Christian, Garza, \& Slaughter, 2011). The findings showed that work engagement is a predisposing factor for job satisfaction. This relationship between work engagement and job satisfaction thus shifted attention from the impact of work engagement on work performance (which is frequently discussed in existing literature) to develop an increased awareness of positive work-related perceptions despite today's increasingly competitive work environment, where employees tend to experience considerable stress. Thus, HRM practices and PSS have the most indirect influence on employees' satisfaction with their work (Demerouti \& Cropanzano, 2010; Wright, Cropanzano, \& Bonett, 2007). Finally, research has been conducted on the work attitudes and values of employees in Chinese Mainland and Taiwan, and there is no difference been reported regarding their perceptions toward job satisfaction and organizational systems (e.g. Harzing \& Pinnington, 2015). Maybe the recent rapid economic development in Chinese Mainland has changed the work attitudes and values among employees in Chinese Mainland, employees in Taiwan have started to adopt less authoritative HRM strategies for employees in Chinese Mainland (Warner, 2013). However, the present study found no significant differences between respondents in Chinese Mainland and Taiwan. We therefore recommend that further investigations should be conducted on work-related behaviors and work environments to identify the differences in the work-related behaviors or attitudes of employees in Taiwan and Chinese Mainland.

\section{Limitations and Future Directions}

This study has some limitations. First, it is difficult to establish the relationship of causality using cross-sectional data. Future studies should therefore obtain 
longitudinal data, particularly in relation to cultural contexts.

Second, while invariance analysis provides a method of testing construct equivalence between the cultural groups, the work pressure of employees is affected by the internal and external environment of the organization (Chen \& Lu, 2013). In particular, cross-cultural adjustment has a significant positive influence on job involvement (Chen \& Wang, 2017). The results of this study using equivalent measurements can help employees in Chinese Mainland and Taiwan to adjust their capabilities through frequent interactions. However, construct equivalence cannot be tested statistically in this study, but the study should be considered qualitative method such as depth interviews when a construct has a wider scope in one culture than in another. To avoid this type of bias, common and culturally specific features should both be included in the measurement.

Third, while the four companies located in Taiwan and Mainland China provide a diverse racial and ethnic group, previous studies using samples from different countries have shown similar associations between organizational support systems, but different outcomes related to performance, engagement, or satisfaction. Thus, we cannot conclude that these characteristics of diversity have had a major impact on our findings because certain findings are consistent with previous research, while others are novel.

\section{Acknowledgements}

We would like to acknowledge the sending questionnaire support of four Taiwan manufacture companies in the conduct of this research and would like to thank Uni-edit (https://uni-edit.net/) for editing and proofreading this manuscript.

\section{Conflicts of Interest}

The author declares no conflicts of interest regarding the publication of this paper.

\section{References}

Alarcon, G., \& Lyons, J. B. (2011). The Relationship of Engagement and Job Satisfaction in Working Samples. The Journal of Psychology, 145, 463-480.

https://doi.org/10.1080/00223980.2011.584083

Alfes, K., Shantz, A. D., Truss, C., \& Soane, E. C. (2013a). The Link between Perceived Human Resource Management Practices, Engagement and Employee Behavior: A Moderated Mediation Model. The International Journal of Human Resource Management, 24, 330-351. https://doi.org/10.1080/09585192.2012.679950

Alfes, K., Truss, C., Soane, E. C., Rees, C., \& Gatenby, M. (2013b). The Relation between Line Manger Behavior, Perceived HRM Practices and Individual Performance: Examining the Mediating Role of Engagement. Human Resource Management, 52, 839-859. https://doi.org/10.1002/hrm.21512

Bakker, A. B., \& Demerouti, E. (2007). The Job Demands-Resources Model: State of the Art. Journal of Managerial Psychology, 22, 309-328.

https://doi.org/10.1108/02683940710733115 
Bal, P. M., \& De Lange, A. H. (2015). From Flexibility Human Resource Management to Employee Engagement and Perceived Job Performance across the Lifespan: A Multi-Sample Study. Journal of Occupational and Organizational Psychology, 88, 126-154. https://doi.org/10.1111/joop.12082

Bal, P. M., Kooij, D. T. A. M., \& De Jong, S. B. (2013). How Do Developmental and Accommodative HRM Enhance Employee Engagement and Commitment? The Role of Psychological Contract and SOC Strategies. Journal of Management Studies, 50, 545-572. https://doi.org/10.1111/joms.12028

Benn, S., Teo, S. T. T., \& Martin, A. (2015). Employee Participation and Engagement in Working for the Environment. Personnel Review, 44, 492-510. https://doi.org/10.1108/PR-10-2013-0179

Blau, P. M. (1964). Exchange and Power in Social Life. New York: John Wiley and Sons.

Brislin, R. W. (1986). The Wording and Translation of Research Instruments. In W. L. Lonner, \& J. W. Berry (Eds.), Field Methods in Cross-Cultural Research (pp.137-164). Newbury Park, CA: Sage.

Byrne, B. M. (2004). Testing for Multi-Group Invariance Using AMOS Graphics: A Road Less Traveled. Structural Equation Modeling, 11, 272-300. https://doi.org/10.1207/s15328007sem1102_8

Byrne, B. M. (2010). Structural Equation Modeling with AMOS: Basic Concepts, Applications, and Programming (2nd ed.). New York: Taylor and Francis Group.

Byrne, B. M., Shavelson, R. J., \& Muthén, B. (1989). Testing for the Equivalence of Factor Covariance and Mean Structures: The Issue of Partial Measurement Invariance. Psychological Bulletin, 105, 456-466. https://doi.org/10.1037/0033-2909.105.3.456

Cammann, C., Fichman, M., Jenkins, G. D., \& Klesh, J. (1983). Michigan Organizational Assessment Questionnaire. In S. E. Seashore, E. E. Lawler, P. H. Mirvis, \& C. Cammann (Eds.), Assessing Organizational Change: A Guide to Methods, Measures, and Practices (pp. 71-138). New York: Wiley-Interscience.

Chen, J. W., \& Lu, L. (2013). The Associations among Job Insecurity, Work Attitudes, and Work Behaviors in the Greater China Region: Affective Organizational Commitment as a Moderator. Organization and Management, 6, 59-92.

Chen, S. Y., \& Wang, S. M. (2017). The Moderating Effect of Cross-Cultural Adjustment on the Relationship between Job Self-Efficacy and Job Involvement. Journal of Business Administration, 113, 91-117.

Cheung, G. W., \& Rensvold, R. B. (2002). Evaluating Goodness-of-Fit Indexes for Testing Measurement Invariance. Structural Equation Modeling, 9, 233-255. https://doi.org/10.1207/S15328007SEM0902_5

Christian, M. S., Garza, A. S., \& Slaughter, J. E. (2011). Work Engagement: A Quantitative Review and Test of Its Relation with Task and Contextual Performance. Personnel Psychology, 64, 89-136. https://doi.org/10.1111/j.1744-6570.2010.01203.x

Cole, M. S., Bruch, H., \& Vogel, B. (2006). Emotion as Mediators of the Relations between Perceived Supervisor Support and Psychological Hardiness on Employee Cynicism. Journal of Organizational Behavior, 27, 463-484. https://doi.org/10.1002/job.381

Demerouti, E., \& Cropanzano, R. (2010). From Thought to Action: Employee Work Engagement and Job Performance. In A. B. Bakker, \& M. P. Leiter (Eds.), Work Engagement: A Handbook of Essential Theory and Research (pp. 147-163). New York: Psychology Press.

Durham C. C., Knight D., \& Locke E. A. (1997). Effetcts of Leader Role, Team-Set Goal Difficulty, Efficacy, and Tactics on Team Effectiveness. Organizational Behavior and 
Eisenberger, R., Stinglhamber, F., Vandenberghe, C., Sucharski, I. L., \& Rhoades, L. (2002). Perceived Supervisor Support: Contributions to Perceived Organizational Support and Employee Retention. Journal of Applied Psychology, 87, 565-573. https://doi.org/10.1037/0021-9010.87.3.565

Fornell, C., \& Larcker, D. F. (1981). Evaluating Structural Equation Models with Unobervables and Measurement Error. Journal of Marketing Research, 18, 39-50. https://doi.org/10.1177/002224378101800104

Giallonardo, L. M., Wang, C. A., \& Iwasie, C. L. (2010). Authentic Leadership of Preceptors: Predictor of New Graduate Nurses' Work Engagement and Job Satisfaction. Journal of Nursing Management, 18, 993-1003. https://doi.org/10.1111/j.1365-2834.2010.01126.x

Gould-Williams, J., \& Davies, F. (2005). Using Social Exchange Theory to Predict the Effects of HRM Practice on Employee Outcomes. Public Management Review, 7, 1-24. https://doi.org/10.1080/1471903042000339392

Harzing, A. W., \& Pinnington, A. (2015). International Human Resource Management (4th ed.). Los Angeles, CA: Sage.

Hays, A. F. (2013). Introduction to Mediation, Moderation, and Conditional Process Analysis: A Regression-Based Approach. New York: The Guilford Press.

Hofstede, G., \& McCrae, R. R. (2004). Culture and Personality Revisited: Linking traits and Dimensions of Culture. Cross-Cultural Research, 38, 52-88.

https://doi.org/10.1177/1069397103259443

Hsu, C. Y., \& Chen, W. Y. (2011). Subordinates' Perception of Managers' Transformational Leadership Style and Satisfaction: A Comparison of Electronic Manufacturing Companies in Mainland China and Taiwan. The International Journal of Human Resource Management, 22, 3097-3108. https://doi.org/10.1080/09585192.2011.560872

Hu, L., \& Bentler, P. M. (1999). Cutoff Criteria for Fit Indexes in Covariance Structure Analysis: Conventional Criteria versus New Alternatives. Structural Equation Modeling, 6, 1-55. https://doi.org/10.1080/10705519909540118

Kahn, W. A. (1990). Psychological Conditions of Personal Engagement and Disengagement at Work. Academy of Management Journal, 33, 697-724. https://doi.org/10.5465/256287

Karatepe, O. M. (2014). The Importance of Supervisor Support for Effective Hotel Employees: An Empirical Investigation in Cameroon. Cornell Hospitality Quarterly, 55, 388-397. https://doi.org/10.1177/1938965513511147

Kline, R. B. (2011). Principles and Practice of Structural Equation Modeling (3rd ed.). New York: The Guilford Press.

Little, T. D. (1997). Mean and Covariance Structures (MACS) Analyses of Cross-Cultural Data: Practical and Theoretical Issues. Multivariate Behavioral Research, 32, 53-76. https://doi.org/10.1207/s15327906mbr3201_3

Lu, L. (2009). 'I or We': Family Socialization Values in a National Probability Sample in Taiwan. Asian Journal of Social Psychology, 12, 145-150. https://doi.org/10.1111/j.1467-839X.2009.01276.x

Lu, L., Cooper, C. L., Kao, S. F., \& Zhou, Y. (2003). Work Stress, Control Beliefs and Well-Being in Greater China: An Exploration of Sub-Cultural Differences between PRC and Taiwan. Journal of Managerial Psychology, 18, 479-510. https://doi.org/10.1108/02683940310494359

Mackinnon, D. P. (2008). Introduction to Statistical Mediation Analysis. Mahwah, NJ: 
Erlbaum.

Paillé, P., Grima, F., \& Bernardeau, D. (2013). When Subordinates Feel Supported by Managers: Investigating the Relationships between Support, Trust, Commitment and Outcomes. International Review of Administrative Sciences, 79, 681-700. https://doi.org/10.1177/0020852313501248

Podsakfoff, P. M., MacKenzie, S. B., Lee, J. Y., \& Podsakoff, N. P. (2003). Common Method Biases in Behavioral Research: A Critical Review of the Literature and Recommended Remedies. Journal of Applied Psychology, 88, 879-903. https://doi.org/10.1037/0021-9010.88.5.879

Podsakoff, P. M., \& Organ, D. W. (1986). Self-Reports in Organizational Research: Problems and Prospects. Journal of Management, 12, 531-544. https://doi.org/10.1177/014920638601200408

Rich, B. L., LePine, J. A., \& Crawford, E. R. (2010). Job Engagement: Antecedents and Effects on Job Performance. Academy of Management Journal, 53, 617-635. https://doi.org/10.5465/amj.2010.51468988

Saks, A. M. (2006). Antecedents and Consequences of Employee Engagement. Journal of Managerial Psychology, 21, 600-619. https://doi.org/10.1108/02683940610690169

Schaufeli, W. B., Bakker, A. B., \& Salanova, M. (2006). The Measurement of Work Engagement with a Short Questionnaire: A Cross-National Study. Educational and Psychological Measurement, 66, 701-716. https://doi.org/10.1177/0013164405282471

Schumacker, R. E., \& Lomax, R. G. (2010). A Beginners Guide to Structural Equation Modeling. New York: Routledge.

Shi, T. (2001). Cultural Values and Political Trust: A Comparison of the People's Republic of China and Taiwan. Comparative Politic, 33, 401-419. https://doi.org/10.2307/422441

Singh, J. (1995). Measurement in Cross-National Research. Journal of international Business Studies, 26, 597-619. https://doi.org/10.1057/palgrave.jibs.8490188

Swanberg, J. E., Mckechnie, S. P., Ojha, M. U., \& James, J. B. (2011). Schedule Control, Supervisor Support and Work Engagement: A Winning Combination for Workers in Hourly Jobs? Journal of Vocational Behavior, 79, 613-624. https://doi.org/10.1016/j.jvb.2011.04.012

Warner, M. (2013). Managing across Diverse Cultures in East Asia: Issues and Challenges in a Changing Globalized World. New York: Routledge. https://doi.org/10.4324/9780203106952

Wright, P. M., \& Boswell, W. R. (2002). Desegregating HRM: A Review and Synthesis of Micro and Macro Human Resource Management Research. Journal of Management, 28, 247-276. https://doi.org/10.1177/014920630202800302

Wright, T. A., Cropanzano, R., \& Bonett, D. G. (2007). The Moderating Role of Employee Positive Well Being on the Relation between Job Satisfaction and Job Performance. Journal of Occupational Health Psychology, 12, 93-104.

https://doi.org/10.1037/1076-8998.12.2.93 


\section{Appendix. Research Scales and Items}

\section{Perceived human resource management practices}

Item 1: I am provided with sufficient opportunities for training or development.

Item 2: This department keeps me informed about business issues and about how well it is doing.

Item 3: There is a clear status difference between management and staff in this department.

Item 4: Team working is strongly encouraged in our department.

Item 5: A rigorous selection process is used to select new recruits.

Item 6: Management involves people when they make decisions that affect them.

Item 7: I feel my job is secure.

Item 8: I feel fairly rewarded for the amount of effort I put into my job.

\section{Perceived supervisor support}

Item 1: My superior really cares about my well-being.

Item 2: My superior strongly considers my goals and values.

Item 3: My superior takes pride in my accomplishments at work.

Item 4: Help is available from my superior when I have a problem.

\section{Work engagement}

Item 1: At my work, I feel bursting with energy.

Item 2: At my job, I feel strong and vigorous.

Item 3: When I get up in the morning, I feel like going to work.

Item 4: I find the work that I do full of meaning and purpose.

Item 5: I am enthusiastic about my job.

Item 6: My job inspires me.

Item 7: Time flies when I am working.

Item 8: When I am working, I forget everything else around me.

Item 9: I feel happy when I am working intensely.

\section{Job satisfaction}

Item 1: In general, I like working here.

Item 2: All in all I am satisfied with my job.

Item 3: In general, I like my job. 